\title{
EFFECTS OF MELIA AZEDARACH L. LEAF AND FRUIT ON MINERALIZATION OF CARBON IN SOIL
}

\author{
Nacide Kizildag, Şahin Cenkseven, Husniye Aka Sagliker ${ }^{* 1}$ and Cengiz Darici \\ Department of Biology, Çukurova University, Adana, Turkey
}

Key words: Azadirachtin, Melia azedarach, Organic matter, Carbon mineralization

\begin{abstract}
Carbon mineralization in soil increased significantly due to additions of pure azadirachtin and powdered leaves and fruits of Melia azedarach L. under in vitro incubation for 30 days at $28^{\circ} \mathrm{C}$. Cumulative respired $\mathrm{C}\left(\mathrm{CO}_{2}\right)$ clearly increased with incubation time in all treatments except in soil mixed with pure azadirachtin (p $<0.001$ ). Carbon mineralization ratio in soils mixed with single doses of powdered leaf and fruit were significantly higher than the other doses tested.
\end{abstract}

Melia azedarach L. (Fam. Meliaceae) has long been recognized as an insecticidal and medicinal plant all over the world. In Argentina it is used as emenagogue, insecticide and vermifuge (Lahitte et al. 1999).

Chemicals like azadirachtin, salanin, meliantriol, nimbin, nimbidin and many fatty acids like oleic, palmitic and linoleic acids exist in the leaves, roots, fruits, seeds and barks of $M$. azedarach (Skellon et al. 1962). As a result of containing many different compounds, this tree has a biocidal effect and it has been used against some harmful fungi, nematodes, acari and especially against various insect groups (Punzo 2005, Nathan 2006). This plant also has antiviral, antibacterial, antiprotozoal and insect repellent agents (Razzaghi-Abyaneh et al. 2005). Azadirachtin is present in the fruits of the plant more than the other parts and is being used as insecticide and herbicide in ecological farming (Sezer and Özalp 2011).

Mineralization of SOM plays a key role in long-term $\mathrm{C}$ sequestration and the readily available soil organic matter (SOM) nutrients required for biogeochemical cycle. The $\mathrm{CO}_{2}$ efflux measured at the soil surface can be considered as soil respiration (Luo and Zhuo 2006). The aim of this investigation was to evaluate the effects of the additions of leaf $(\mathrm{L})$ and fruit $(\mathrm{F})$ containing the same and double amounts of soil carbon and pure azadirachtin on carbon mineralization in soil.

the soil samples for the present investigation were collected in April 2009 from underneath three M. azedarach trees present in the campus of Çukurova University in Adana, Turkey. After the removal of litter layer, soil sample was taken from the first $0-10 \mathrm{~cm}$. After collection, the three soil samples were mixed thoroughly, air-dried and sieved through a $2 \mathrm{~mm}$ mesh sieve before analysis.

$\mathrm{pH}$ (8.08) was measured in a 1:2.5 soil-to-water suspension with a pH meter (Jackson 1958). $\mathrm{CaCO}_{3}$ content (28.4\%) was measured with a Scheibler calcimeter (Allison and Moddie 1965). Organic carbon content of soil (1.89\%), leaf (49.8\%) and fruit $(61.1 \%)$ were determined by the Anne Method (Duchaufour 1970) and the total nitrogen content of soil $(0.14 \%)$, leaf $(0.60 \%)$ and fruit $(0.15 \%)$ by the Kjeldahl Method (Duchaufour 1970). C:N ratio of soil (13.9) was also determined.

*Author for correspondence: <hasagliker@osmaniye.edu.tr>. ${ }^{1}$ Department of Biology, Osmaniye Korkut Ata University, Osmaniye, Turkey. 
Pure azadirachtin solution (NeemAzal ${ }^{\circledR}-\mathrm{T} / \mathrm{S}, 10 \mathrm{~g} / \mathrm{l}$ azadirachtin A) used in this study contains $10 \mathrm{~g}$ azadirachtin A in one liter. Agricultural usage of azadirachtin solution in the field (in situ) is $50 \mathrm{ml}$ in 10 liters $(0.5 \mathrm{~g} / 50 \mathrm{ml})$. Collected leaves and fruits of $M$. azedarach were mixed directly with the soil after being powdered. Azadirachtin analysis of leaf and fruit samples has been done after Dai et al. 1999.

Six treatments of azadirachtin, being control soil, $0.29(\mathrm{~L}), 0.58(2 \times \mathrm{L}), 1.18(\mathrm{~F}), 2.36(2 \times \mathrm{F})$ and $150 \mathrm{mg} / 100 \mathrm{~g}$ (pure azadirachtin), were used. In an incubation vessel (500 ml cap.) $80 \mathrm{~g}$ soils were placed $80 \%$ field capacity (Schaefer 1967). The $\mathrm{CO}_{2}$ produced in soil was absorbed periodically in $40 \mathrm{ml}$ of saturated $\mathrm{Ba}(\mathrm{OH})_{2}$ solution in small tubes. The incubation vessels were kept closed. Empty vessels were used as blanks. $\mathrm{CO}_{2}$ produced as a result of microbial respiration was measured at every three days by titration with $\mathrm{N} / 22$ oxalic acid. The incubation was carried out in a dark, temperature controlled incubator at 28C for 30 days. The ratios (\%) of carbon mineralization of soils were calculated by dividing the cumulated $\mathrm{C}\left(\mathrm{CO}_{2}\right)$ produced in 30 days of the incubation period to the total organic carbon of the corresponding soil sample.

To determine the differences in carbon mineralization over incubation time among the treatments, a Repeated Measures (General Linear Model) analysis was performed (Kleinbaum et al. 1998). Results are given in figures as mean values \pm standard errors of three replicates. Differences between the data were declared as significant at the $\mathrm{p}<0.05$. All statistical analyses were carried out using SPSS v.11.5.

Changes in $\mathrm{C}$ mineralization with incubation time for all treatments with leave and fruit mixed soils were found significant when compared with control $(p<0.05)$. It was also observed that $\mathrm{C}$ mineralization of four treatments was significantly higher $(\mathrm{p}<0.05)$ than the soil with pure azadirachtin (Fig. 1). Addition of substrate might increase microbial activity in M. azedarach soil. Similar results were also observed elsewhere (Aggangan et al. 1999, Aka and Darıcı 2005). When $M$. azedarach leaves and fruits were added to the soils, it was observed that azadirachtin leaves $(0.29 \mathrm{mg})$ and fruits $(1.18 \mathrm{mg})$ did not act like pure azadirachtin. It is possible to conclude that soil microorganisms used leaf and fruit organic carbon as energy source. Cumulative respired $\mathrm{C}\left(\mathrm{CO}_{2}\right)$ increased with increasing amounts of leaf litter addition when leaf litter was mixed with the native forest soil (Aggangan et al. 1999).

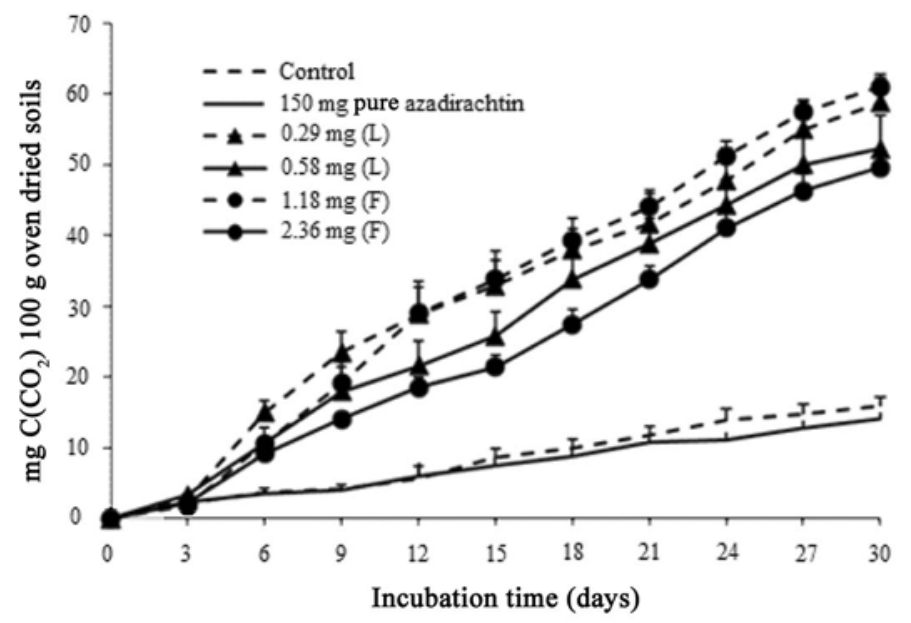

Fig. 1. Cumulative $\mathrm{C}$ respired during incubation of soil treated with pure azadirachtin and leaves (L) and fruits (F) of M. azedarach. 
A significant increase $(\mathrm{p}<0.05)$ in carbon mineralization ratio was observed when both single doses of leaf and fruit were compared with the other treatments (Fig. 2). The carbon ratios with single doses of leaf and fruit could be optimum threshold for microorganisms because of their efficient activities in the soils. This threshold can only be determined by the triangle of soil-plantmicroorganism. Soil organic-C content, soil $\mathrm{C} / \mathrm{N}$ ratio and DOM-C may influence microbial community and their activities (Marschner et al. 2003). After subtracting $C$ mineralization ratio of control soil, $0.79 \%$ of leaf carbon and $0.85 \%$ of fruit carbon were mineralized in soils treated with leaves and fruits. It can be concluded that azadirachtin has no inhibition effect on $\mathrm{C}$ mineralization at the doses used. When $\mathrm{C}$ mineralization ratio of soils treated with leaves (0.58 mg azadirachtin) and fruits (2.36 mg azadiracthin) were compared with the control soil, only $0.09 \%$ of leaf carbon and $0.04 \%$ of fruit carbon were found to be mineralized. Microorganisms realized mineralization at rather low levels in double doses of leaf and fruit treatments. These results might be explained with reducing effect to mineralization of excess organic matter. The quantities of $M$. azedarach leaves and fruits added to soil might be at the unsuitable limits for the homeostasis of soil. New sources that force the homeostasis of the soil, even the energy sources may only be used in the permitting limits of this homeostasis (Marschner et al. 2003, Steenwerth et al. 2003).

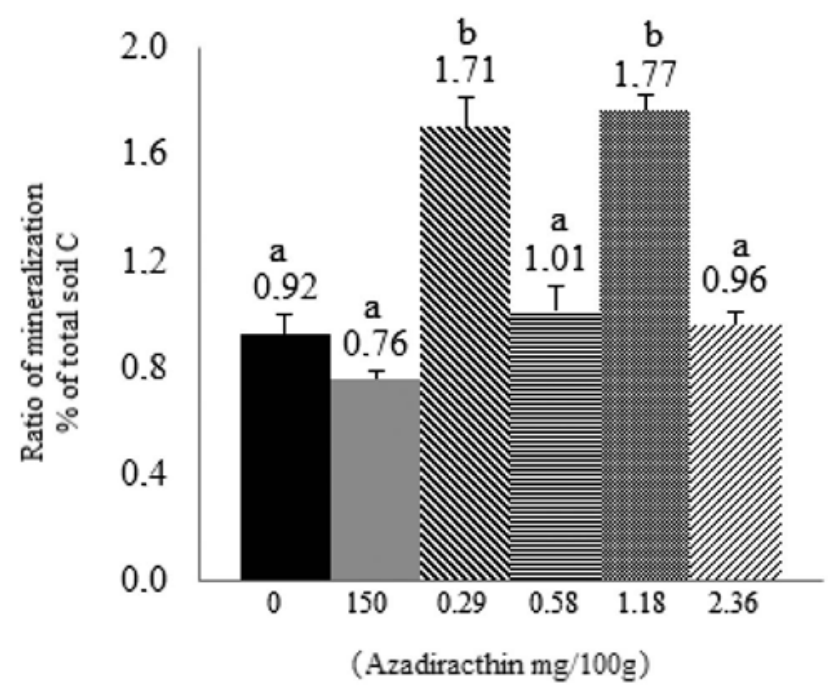

Fig. 2. Organic carbon mineralization ratio $\left(\mathrm{R}_{\mathrm{m}}, \%\right)$ in $M$. azedarach soil influenced by new leaf and fruit at the end of incubation period (30 days). Different letters denote significant differences between treatments at $\mathrm{p}<0.05$ level.

It could be concluded that $M$. azedarach soils treated with $M$. azedarach leaves and fruits at the same and double amounts of soil carbon have similar effects on soil microorganisms. Some natural compounds like azadirachtin, tannic acid, etc. in low amounts can be used as carbon source by microorganisms (Kraal et al. 2009). Effects of azadirachtin on microbial activity can be better understood by carrying out similar studies on different soils of Mediterranean basin.

\section{Acknowledgement}

The present study was supported by the Research and Application Center of Çukurova University, Turkey under the Project No. FEF2009YL38 which is duly acknowledged with thanks. 


\section{References}

Allison LE and CD Moodie 1965. Carbonate. American Soc. Agron. 9: 1379-1396.

Aggangan RT, AM O’Connell, JF McGrath and B Dell 1999. The effects of Eucalyptus globules Labill. leaf litter on $\mathrm{C}$ and $\mathrm{N}$ mineralization in soils from pasture and native forest. Soil Biol. Biochem. 31: 14811487.

Aka H and C Darıcı 2005. Carbon and nitrogen mineralization in carob soils with Kermes oak and Aleppo pine leaf litter. Eur. J. Soil Biol. 41: 31-38.

Dai J, VA Yaylayan, GS Vijayaraghvan and JR Pare 1999. Extraction and colorimetric determination of azadirachtin-related limonoids in neem seed kernel. J. Agr. Food Chem. 47: 3738-3742.

Duchaufour P 1970. Precis de Pedologie. Masson et $C^{1 \mathrm{e}}$, Paris. 83 pp. France.

Jackson ML 1958. Soil Chemical Analysis. Prentice-Hall, Inc., Englewood Cliffs, New Jersey. 18 pp.

Kleinbaum DG, LL Kupper, KE Muller and A Nizam 1998. Applied Regression Analysis and Other Multivariable Methods. Duxbury Press, California. 92 pp.

Kraal P, GJN Klaas, J Kaal and A Tietema 2009. Carbon respiration and nitrogen dynamics in Corsican pine litter amended with aluminium and tannins. Soil Biol. Biochem. 41: 2318-2327.

Lahitte HB, JA Hurrell, JJ Valla, L Jankowski, D Bazzano and AJ Hernandez 1999. Biota ríoplatense IV. Arbolesurbanos. Lola, Buenos Aires, Argentina, 56 pp.

Luo Y and X Zhou 2006. Soil Respiration and the Environment. Academic Press, USA. 45 pp.

Marschner P, E Kandeler and B Marschner 2003. Structure and function of the soil microbial community in a long-term fertilizer experiment. Soil Biol. Biochem. 35: 453-461.

Nathan S 2006. Effects of Melia azedarach on nutrition physiology and enzyme activities of the rice leaf folder Chaphalocloris medinalis (Guenee) (Lepidoptera: Pyralidae). Pestic. Biochem. Phys. 84: 98-108.

Punzo F 2005. Neem seed extract containing azadirachtin effects mortality, growth and immunological function in the whip scorpion Mastigoproctus giganteus (Lucas) (Arachnida, Uropygi). B. Environ. Contam. Tox. 75: 684-690.

Razzaghi-Abyaneh M, A Allameh, T Tiraihi, M Shams-Ghahfarokhi and M Ghorbanian 2005. Morphological alterations in toxigenic Aspergillus parasiticus exposed to neem (Azadirachta indica) leaf and seed aqueous extracts. Mycopathologia 159: 565-570.

Schaefer R 1967. Characteres et evolution des activites microbiennes dans unechaine de sols hidromorphes mesotrophiques de la plained’Alsace. Rev. Ecol. Biol. Sol 4: 567-592.

Sezer B and P Özalp 2011. Azadirachtinin Galleria mellonella Larvalarında Total Glikojen Miktarına Etkisi. Ekoloji 81: 67-72.

Skellon JH, S Thorburn, J Spence and SN Chatterjee 1962. The fatty acids of neem oil and their reduction products. J. Sci. Food Agr. 13: 639-643.

Steenwerth KL, LE Jackson, FJ Calderón, MR Stromberg and KM Scow 2003. Soil microbial community composition and land use history in cultivated and grassland ecosystems of coastal California. Soil Biol. Biochem. 35: 489-500.

(Manuscript received on 14 March, 2013; revised on 23 April, 2013) 